\title{
AV Nodal Ablation in Heart Failure Patients with Atrial Fibrillation
}

Osmar Antonio Centurion ${ }^{1,2 *}$, Karina Elizabeth Scavenius ${ }^{2}$, Laura Beatriz Garcia ${ }^{1}$, Orlando R Sequeira ${ }^{2}$ and Luis M Mino ${ }^{2}$

${ }^{1}$ Department of Health Science's Investigation, Sanatorio Metropolitano, Fernando de la Mora, Paraguay

2Division of Cardiovascular Medicine, Clinical Hospital, Asunción National University (UNA), San Lorenzo, Paraguay

\begin{abstract}
The optimal medical treatment can fail in the intention to improve symptoms and quality of life of heart failure (HF) patients with severe left ventricular dysfunction and atrial fibrillation (AF) with uncontrolled ventricular rate. In these refractory cases to medical management, the necessity to utilize cardiac resynchronization therapy (CRT), or the need to use catheter ablation, or both, emerges in order to achieve hemodynamic improvement. Several clinical studies with CRT demonstrated structural and functional ventricular improvement. Moreover, there are additional beneficial effects in left ventricular remodeling. It was demonstrated that there is a significant improvement in left ventricular ejection fraction, and a significant decrease in end systolic and end diastolic volumes. However, CRT may be interrupted in over $30 \%$ of patients after successful implantation of a device and the most common reason for CRT interruption is the development of AF in $18 \%$ of the cases. Those patients whom do not respond to drug therapy will require atrioventricular nodal (AVN) catheter ablation in order to restore $100 \%$ CRT functionality and improvements in clinical outcomes. There are interesting published data documenting significant acute and longterm improvement in left ventricular function, cardiac performance, symptoms, exercise tolerance, clinical outcomes, and quality of life in selected HF patients with paroxysmal and persistent drug-refractory AF who have undergone AVN ablation and permanent pacemaker implantation.
\end{abstract}

Keywords: AV nodal catheter ablation; Atrial fibrillation; Congestive heart failure

\section{Introduction}

Congestive heart failure (HF) per se has a reserved prognosis in patients with low left ventricular ejection fraction, and this prognosis even worsens if atrial fibrillation (AF) develops. AF and $\mathrm{HF}$ are common cardiovascular diseases with high comorbidities and mortality and severe prognostic implications [1-5]. AF usually generates rapid ventricular response, irregularity of ventricular rhythm, loss of the atrial kick and organized atrial contribution to cardiac output, and in some cases with persistent or permanent AF, tachycardiainduced cardiomyopathy [6-13]. Aging has a profound impact on the histological and thus, electrophysiological changes in the human atrial myocardium which contribute to the higher prevalence of $\mathrm{AF}$ in the elderly [14-20]. The prevalence of AF in patients with advanced HF reaches up to $40 \%$. AF is considered to be an independent predictor of morbidity and mortality increasing the risk of death and hospitalization in HF patients [11-13].

The optimal medical treatment can fail in the intention to improve symptoms and quality of life of HF patients with severe left ventricular dysfunction and AF with uncontrolled ventricular rate [21-24]. In these refractory cases to medical management, the necessity to utilize cardiac resynchronization therapy (CRT), or the need to use catheter ablation, or both, emerges in order to achieve hemodynamic improvement. Several clinical studies with CRT demonstrated structural and functional ventricular improvement. Moreover, there are additional beneficial effects in left ventricular remodeling. It was demonstrated that there is a significant improvement in left ventricular ejection fraction, and a significant decrease in end systolic and end diastolic volumes at 3 months of followup $[25,26]$. Importantly, these beneficial effects are dependent on continuous biventricular pacing since interruption of electric stimulation produce a progressive but not immediate loss of effect. However, CRT may be interrupted in over $30 \%$ of patients after successful implantation of a device and the most common reason for CRT interruption is the development of AF in 18\% of the cases. Indeed, it was reported that almost $20 \%$ of patients who undergo successful implantation of a defibrillator capable of delivering CRT develop an episode of AF with a rapid ventricular response, which at least temporarily results in the inability to deliver CRT [2527]. Those patients whom do not respond to drug therapy will require atrioventricular nodal (AVN) catheter ablation in order to restore $100 \%$ CRT functionality and improvements in clinical outcomes. There are interesting published data documenting significant acute and longterm improvement in left ventricular function, cardiac performance, symptoms, exercise tolerance, clinical outcomes, and quality of life in selected HF patients with paroxysmal and persistent drug-refractory $\mathrm{AF}$ who have undergone AVN ablation and permanent pacemaker implantation.

\section{AV Nodal Ablation}

There are some data available from meta-analysis which reported beneficial evidence in favour of AVN catheter ablation followed by permanent pacemaker implantation in symptomatic, drug-refractory AF patients. In his meta-analysis, Wood et al. [28] examined 1181 patients from 21 different studies and found that exercise duration, ejection fraction, quality of life, symptoms, and hospital admissions improved significantly. In this study they observed that the only parameter that did not reach statistical significance was LV fractional shortening. However, this last parameter showed a tendency towards improvement. In another meta-analysis performed by Chatterjee et al.

*Corresponding author: Osmar Antonio Centurion, Professor of Medicine, Department of Health Science's Investigation, Sanatorio Metropolitano, Fernando de la Mora, Paraguay, Tel: 595021421423 E-mail: osmarcenturion@hotmail.com

Received December 13, 2017; Accepted December 27, 2017; Published December 29, 2017

Citation: Centurion OA, Scavenius KE, Garcia LB, Sequeira OR, Mino LM (2017) AV Nodal Ablation in Heart Failure Patients with Atrial Fibrillation. J Cardiovasc Dis Diagn S2: 003. doi:10.4172/2329-9517.S2-003

Copyright: (c) 2017 Centurion OA, et al. This is an open-access article distributed under the terms of the Creative Commons Attribution License, which permits unrestricted use, distribution, and reproduction in any medium, provided the original author and source are credited. 
[29], they analyzed a total of 5 randomized or prospective trials with a total of 314 patients for efficacy review, another 11 studies (810 patients) for effectiveness review, and 47 studies (5632 patients) for safety review.

These authors found in this study that in the therapeutic management of refractory AF, AVN catheter ablation is associated with improvement in symptoms and quality of life, with a low incidence of procedure morbidity [29]. In addition, in patients with reduced systolic function, AVN ablation demonstrated also significantly improved echocardiographic outcomes relative to medical therapy alone. However, their results demonstrated also that there was no statistical difference in all-cause mortality, exercise duration, and left ventricular ejection fraction between AVN ablation and medical therapy groups [29]. Therefore, with this interventional procedure of "ablate and pace" we are offering our HF patients with AF a better quality of life due to hemodynamic improvements, but no longer survival.

Right ventricular pacing has been associated to deleterious alterations in left ventricular function. Hence, in order to avoid the noxious effects of long-term right ventricular pacing on left ventricular function after AVN catheter ablation [30], biventricular pacing has been proposed as an alternative pacing method. CRT significantly reduces hospitalizations for $\mathrm{HF}$, and significantly improves functional capacity and left ventricular function in comparison with right ventricular pacing only [31-33]. Therefore, the current guidelines recommend CRT in patients with $\mathrm{AF}$ and left ventricular dysfunction who are candidates for AVN catheter ablation with an indication IIa level of evidence B [34,35]. Indeed, AVN ablation followed by CRT is an established strategy for improving symptoms and morbidity in patients with permanent $\mathrm{AF}$, reduced left ventricular ejection fraction, and uncontrolled ventricular rate.

\section{Discussion}

Geelen et al. [36] stated that AVN ablation may predispose patients to an increased risk of sudden cardiac death. Early studies reported 1 -year sudden death rates varying from $0 \%$ to $9 \%[28,37]$. The majority of those patients who developed sudden cardiac death had a significant number of risk factors, including reduced left ventricular ejection fraction, advanced HF, and a history of ventricular arrhythmias $[38,39]$. Bradley et al. [40] found no significant difference in mortality when the "ablate and pace" procedure was compared to medical treatment. They demonstrated an all-cause mortality of $3.5 \%$ with AVN ablation and $3.3 \%$ with drug therapy at 1 year of follow-up in their meta-analysis of randomized trials comparing AVN catheter ablation with permanent pacemaker implantation and drug therapy. The rate of sudden cardiac death further decreased to $0.2 \%$ when pacing was incremented to an initial lower rate of $90 \mathrm{bpm}$ [41]. Actually, sudden cardiac death is not a subject of concern anymore $[42,43]$. The 1 year total mortality is $6.3 \%$ and the rate of sudden cardiac death is only $2 \%$, which is similar to that of control patients with AF who remain on drug therapy $[28,44]$.

\section{Conclusion}

In conclusion, there are beneficial effects in left ventricular function, cardiac performance, symptoms, exercise tolerance, clinical outcomes, and quality of life in selected HF patients with paroxysmal and persistent drug-refractory AF who have undergone AVN ablation and permanent pacemaker implantation. Current guidelines recommend CRT in HF patients with AF whom are candidates for AVN catheter ablation with an indication IIa level of evidence B.

\section{References}

1. Jani BD, Nicholl BI, McQueenie R, Connelly DT, Hanlon P, et al. (2017)
Multimorbidity and co-morbidity in atrial fibrillation and effects on survival: Findings from UK Biobank cohort. Europace

2. Guerra F, Brambatti M, Nieuwlaat R, Marcucci M, Dudink E, et al. (2017) Symptomatic atrial fibrillation and risk of cardiovascular events: data from the Euro Heart Survey. Europace

3. Hohendanner F, Heinzel FR, Blaschke F, Pieske BM, Haverkamp W, et al. (2017) Pathophysiological and therapeutic implications in patients with atrial fibrillation and heart failure. Heart Fail Rev 1-10.

4. Carson PE, Johnson GR, Dunkman WB, Fletcher RD, Farrell L, et al. (1993) The influence of atrial fibrillation on prognosis in mild to moderate heart failure: The V-HeFT studies. Circulation 87: 102-110.

5. Modin D, Sengeløv M, Jørgensen PG, Bruun NE, Olsen FJ, et al. (2017) Globa longitudinal strain corrected by RR interval is a superior predictor of all-cause mortality in patients with systolic heart failure and atrial fibrillation. ESC Heart Fail

6. Birnie D, Hudnall H, Lemke B, Aonuma K, Lee KL, et al. (2017) Continuous optimization of cardiac resynchronization therapy reduces atrial fibrillation in heart failure patients: Results of the Adaptive Cardiac Resynchronization Therapy Trial. Heart Rhythm 14: 1820-1825

7. Sun L, Yan S, Wang X, Zhao S, Li H, et al. (2017) Metoprolol prevents chronic obstructive sleep apnea-induced atrial fibrillation by inhibiting structural sympathetic nervous and metabolic remodeling of the atria. Sci Rep 2: 14941.

8. Centurion OA (2009) Atrial fibrillation complicating congestive heart failure: Electrophysiological aspects and its deleterious effect on cardiac resynchronization therapy. J Atrial Fib 1: 417-429.

9. Pozzoli M, Cioffi G, Traversi E, Pinna GD, Cobelli F, et al. (1998) Predictors of primary atrial fibrillation and concomitant clinical and hemodynamic changes in patients with chronic heart failure: A prospective study in 344 patients with baseline sinus rhythm. J Am Coll Cardiol 32: 197-204.

10. Joy PS, Gopinathannair R, Olshansky B (2017) Effect of ablation for atria fibrillation on heart failure readmission rates. Am J Cardiol 120: 1572-1577.

11. Elshazly MB, Senn T, Wu Y, Lindsay B, Saliba W, et al. (2017) Impact of atria fibrillation on exercise capacity and mortality in heart failure with preserved ejection fraction: Insights from cardiopulmonary stress testing. $\mathrm{J}$ Am Heart Assoc 6: e006662.

12. Kannek WB, Abbot RD, Savage DD, McNamara PM (1982) Epidemiologic features of chronic atrial fibrillation: The Framingham study. N Engl J Med 306 1018-1022.

13. Dries DL, Exner DV, Gersh BJ, Domanski MJ, Waclawiw MA, et al. (1998) Atria fibrillation is associated with an increased risk for mortality and heart failure progression in patients with asymptomatic and symptomatic left ventricular systolic dysfunction: A retrospective analysis of the SOLVD trials. J Am Col Cardiol 32: 695-703.

14. Grandi E, Dobrev D (2017) Non-ion channel therapeutics for heart failure and atrial fibrillation: Are CaMKII inhibitors ready for clinical use? J Mol Cell Cardiol.

15. Gasparini M, Galimberti P (2017) Atrial fibrillation and cardiac resynchronization therapy. Curr Opin Cardiol.

16. Bourassa MG, Gurné O, Bangdiwala SI, Ghali JK, Young JB, et al. (1993) Natural history and patterns of current practice in heart failure. $\mathrm{J}$ Am Coll Cardiol 22: 14-19.

17. Mathew J, Hunsberger S, Fleg J, Mc Sherry F, Williford W, et al. (2000) Incidence, predictive factors, and prognostic significance of supraventricula tachyarrhythmias in congestive heart failure. CHEST 118: 914-922.

18. Davies MJ, Pomerance A (1972) Pathology of atrial fibrillation in man. Br Heart J 34: $520-525$

19. Lev M (1954) Aging changes in the human sinoatrial node. J Geront 9: 1.

20. Davies MJ, Pomerance A (1972) Quantitative study of aging changes in the human sinoatrial node and internodal tracts. Br Heart J 1972 34: 150-152.

21. Hudson REB (1960) The human pacemarker and its pathology. Br Heart J 22 153

22. Centurion OA, Isomoto S, Shimizu A, Konoe A, Kaibara M, et al. (2003) The effects of aging on atrial endocardial electrograms in patients with paroxysmal atrial fibrillation. Clin Cardiol 26: 435-438.

23. Centurión OA, Shimizu A, Isomoto S, Konoe A, Kaibara M, et al. (2005) 
Influence of advancing age on fractionated right atrial endocardial electrograms. Am J Cardiol 96: 239-242.

24. Centurion OA, Fukatani M, Konoe A, Tanigawa M, Shimizu A, et al. (1992) Different distribution of abnormal endocardial electrograms within the right atrium in patients with sick sinus syndrome. Br Heart J 68: 596- 600.

25. Yu CM, Chau E, Sanderseon JE, Fan K, Tang MO, et al. (2002) Tissue doppler echocardiographic evidence of reverse remodeling and improved synchronicity by simultaneously delaying regional contraction after biventricular pacing therapy in heart failure. Circulation 105: 438-445.

26. Adamson PB, Kleckner K, Van Hout WL, Srinivasan S, Abraham WT, et al. (2003) Cardiac resynchronization therapy improves heart rate variability in patients with symptomatic heart failure. J Am Coll Cardiol 108: 266-269.

27. Knight BP, Desai A, Coman J, Faddis M, Yong $P$ (2004) Long-term retention of cardiac resynchronization therapy. J Am Coll Cardiol 44: 72-77.

28. Wood MA, Brown-Mahoney C, Kay GN, Ellenbogen KA (2000) Clinical outcomes after ablation and pacing therapy for atrial fibrillation: A metaanalysis. Circulation 101: 1138-1144.

29. Chatterjee NA, Upadhyay GA, Ellenbogen KA, McAlister FA, Choudhry NK, et al. (2012) Atrioventricular nodal ablation in atrial fibrillation: A meta-analysis and systematic review. Circ Arrhythm Electrophysiol 5: 68-76

30. Lim KT, Davis MJ, Powell A, Arnolda L, Moulden K, et al. (2007) Ablate and pace strategy for atrial fibrillation: Long-term outcome of AIRCRAFT trial. Europace 9: 498-505.

31. Stavrakis S, Garabelli P, Reynolds DW (2012) Cardiac resynchronization therapy after atrioventricular junction ablation for symptomatic atrial fibrillation: A meta-analysis. Europace 14: 1490-1497.

32. Doshi RN, Daoud EG, Fellows C, Duran A, Hamdan MH, et al. (2005) Left ventricular-based cardiac stimulation post $A V$ nodal ablation evaluation (the PAVE study). J Cardiovasc Electrophysiol 16: 1160-1165.

33. Orlov MV, Gardin JM, Slawsky M, Bess RL, Cohen G, et al. (2010) Biventricula pacing improves cardiac function and prevents further left atrial remodeling in patients with symptomatic atrial fibrillation after atrioventricular node ablation. Am Heart J 159: 264-270.

34. Brignole M, Auricchio A, Baron-Esquivias G, Bordachar P, Boriani G, et al. (2013) 2013 ESC guidelines on cardiac pacing and cardiac resynchronization therapy: The task force on cardiac pacing and resynchronization therapy of the European Society of Cardiology (ESC). Developed in collaboration with the European Heart Rhythm Association (EHRA). Europace 15: 1070-1118.
35. Dickstein K, Vardas PE, Auricchio A, Daubert JC, Linde C, et al. (2010) 2010 focused update of ESC guidelines on device therapy in heart failure: an update of the 2008 ESC guidelines for the diagnosis and treatment of acute and chronic heart failure and the 2007 ESC guidelines for cardiac and resynchronization therapy. Developed with the special contribution of the Heart Failure Association and the European Heart Rhythm Association. Europace 12: $1526-1536$

36. Geelen P, Brugada J, Andries E, Brugada P (1997) Ventricular fibrillation and sudden death after radiofrequency catheter ablation of the atrioventricular junction. Pacing Clin Electrophysiol 20: 343-348.

37. Twidale N, McDonald T, Nave K, Seal A (1998) Comparison of the effects of AV nodal ablation versus AV nodal modification in patients with congestive heart failure and uncontrolled atrial fibrillation. Pacing Clin Electrophysiol 21 641-651.

38. Yeung-Lai-Wah JA, Qi A, Uzun O, Humphries K, Kerr CR (2002) Long-term survival following radiofrequency catheter ablation of atrioventricular junction for atrial fibrillation: Clinical and ablation determinants of mortality. J Interv Card Electrophysiol 6: 17-23.

39. Ozcan C, Jahangir A, Friedman PA, Hayes DL, Munger TM, et al. (2002) Sudden death after radiofrequency ablation of the atrioventricular node in patients with atrial fibrillation. J Am Coll Cardiol 40: 105-110.

40. Bradley DJ, Shen WK (2007) Atrioventricular junction ablation combined with either right ventricular pacing or cardiac resynchronization therapy for atrial fibrillation: The need for large-scale randomized trials. Heart Rhythm 4: 224-232.

41. Wang RX, Lee HC, Hodge DO, Cha YM, Friedman PA, et al. (2013) Effect of pacing method on risk of sudden death after atrioventricular node ablation and pacemaker implantation in patients with atrial fibrillation. Heart Rhythm10: 696-701.

42. Garcia B, Clementy N, Benhenda N, Pierre B, Babuty D, et al (2016) Mortality after atrioventricular nodal radiofrequency catheter ablation with permanent ventricular pacing in atrial fibrillation outcomes from a controlled nonrandomized study. Circ Arrhythm Electrophysiol 9: e003993.

43. Wang RX, Lee HC, Li JP, Hodge DO, Cha YM, et al. (2017) Sudden death and its risk factors after atrioventricular junction ablation and pacemake implantation in patients with atrial fibrillation. Clin Cardiol 40: 18-25.

44. Ozcan C, Jahangir A, Friedman PA, Patel PJ, Munger TM, et al. (2001) Long term survival after ablation of the atrioventricular node and implantation of permanent pacemaker in patients with atrial fibrillation. $\mathrm{N}$ Engl $\mathrm{J}$ Med 344 1043-1051. 